\title{
Contaminação por microrganismos nos diversos tipos de tábuas de corte
}

\author{
Contamination by microorganisms in the various types of cutting boards \\ Contaminación por microorganismos em diferentes tipos de tablas de cortar
}

Recebido: 01/10/2021 | Revisado: 08/10/2021 |Aceito: 14/10/2021 | Publicado: 17/10/2021

\author{
Sabrina Ribeiro de Moura \\ ORCID: https://orcid.org/0000-0002-0498-9827 \\ Instituto Educacional Santa Catarina, Brasil \\ E-mail: sabrinaribeiromoura@gmail.com \\ Eduarda Mendes da Silva \\ ORCID: https://orcid.org/0000-0003-0186-3011 \\ Instituto Educacional Santa Catarina, Brasil \\ E-mail: mendesduda147@gmail.com \\ Mara Soares de Almeida Mota \\ ORCID: https://orcid.org/0000-0002-2068-3481 \\ Instituto Educacional Santa Catarina, Brasil \\ E-mail: mara.almeida06@gmail.com
}

\begin{abstract}
Resumo
$\mathrm{Na}$ manipulação de diversos alimentos pode ocorrer contaminação devido à forma irregular no manuseio dos utensílios, aumentando o risco da transmissão de microrganismos de um alimento para o outro, na maioria dos casos a contaminação ocorre pela inadequada higienização. As tábuas de corte na cozinha são bastante utilizadas, e esse utensílio, com o acúmulo de cortes, reentrâncias e orifícios, tornam-se um local hospitaleiro para a proliferação de microrganismos; as tábuas de vidro, plástico e madeira, são as mais utilizadas, porém a que possui maior risco de contaminação é a de madeira. Esta pesquisa tem como objetivo identificar o nível de contaminação por microrganismos em de tábuas de corte e o tipo mais adequado para a utilização de forma segura. O presente artigo foi desenvolvido por meio de uma revisão integrativa em artigos científicos encontrados nas bases de dados eletrônicas, Google Acadêmico, PubMed e SciELO que abordaram a análise microbiológica de tábuas de corte. Os resultados das pesquisas apresentaram a prevalência de microrganismos aeróbios mesófilos, leveduras, fungos e bactérias da família Enterobacteriaceae. Para prevenção de contaminações cruzadas nos alimentos, é indicado o uso de tábuas de polietileno coloridas, onde cada cor é designada para o preparo de um único tipo de alimento, além de, não negligenciar a limpeza antes e após o uso dos utensílios.
\end{abstract}

Palavras-chave: Tábuas de corte; Alimentos contaminados; Microrganismos; Contaminação alimentar.

\begin{abstract}
In the handling of various foods, contamination can occur due to the irregular way in which utensils are handled, increasing the risk of transmission of microorganisms from one food to another. In most cases, contamination occurs due to inadequate sanitation. Cutting boards in the kitchen are widely used, and this utensil, with the accumulation of cuts, recesses and holes, becomes a hospitable place for the proliferation of microorganisms; glass, plastic and wood boards are the most used, but the one with the greatest risk of contamination is wood. This research aims to identify the level of contamination by microorganisms in cutting boards and the most suitable type for safe use. This article was developed through an integrative review of scientific articles found in electronic databases, Academic Google, PubMed and SciELO that addressed the microbiological analysis of cutting boards. The survey results showed the prevalence of mesophilic aerobic microorganisms, yeasts, fungi and bacteria of the Enterobacteriaceae family. To prevent cross-contamination in food, the use of colored polyethylene boards is recommended, where each color is designed for the preparation of a single type of food, in addition to not neglecting cleaning before and after using utensils.
\end{abstract}

Keywords: Cutting boards; Contaminated food; Microorganisms; Food contamination.

\section{Resumen}

En el manejo de diversos alimentos se puede producir contaminación por la forma irregular en la que se manipulan los utensilios, aumentando el riesgo de transmisión de microorganismos de un alimento a otro, en la mayoría de los casos la contaminación se produce por un saneamiento inadecuado. Las tablas de cortar en la cocina son muy utilizadas, y este utensilio, con la acumulación de cortes, rebajes y huecos, se convierte en un lugar acogedor para la proliferación de microorganismos; Los tableros de vidrio, plástico y madera son los más utilizados, pero el que presenta mayor riesgo de contaminación es la madera. Esta investigación tiene como objetivo identificar el nivel de contaminación 
por microorganismos en las tablas de cortar y el tipo más adecuado para un uso seguro. Este artículo fue desarrollado a través de una revisión integradora de artículos científicos encontrados en bases de datos electrónicas, Academic Google, PubMed y SciELO que abordaron el análisis microbiológico de tablas de cortar. Los resultados de la encuesta mostraron la prevalencia de microorganismos aerobios mesófilos, levaduras, hongos y bacterias de la familia Enterobacteriaceae. Para evitar la contaminación cruzada en los alimentos, se recomienda el uso de tableros de polietileno de colores, donde cada color está diseñado para la preparación de un solo tipo de alimento, además de no descuidar la limpieza antes y después de usar los utensilios.

Palabras clave: Tablas de cortar; Comida contaminada; Microorganismos; Contaminación alimenticia.

\section{Introdução}

A segurança alimentar visa promover saúde e prevenção de doenças, pois o consumo de alimentos contaminados podem desenvolver problema de saúde pública, tanto quanto um risco para as empresas do setor alimentício, pois as doenças transmitidas por alimentos são comuns. A má higienização pessoal dos manipuladores de alimentos e dos utensílios utilizados por eles, são fatores relacionados a contaminação dos alimentos (Pinheiro, et al., 2010).

Tratando-se das cozinhas domiciliares é comum encontrar meios para a ocorrência de contaminação dos alimentos, por exemplo, as superfícies das tábuas de corte favorecem a adesão, multiplicação e a sobrevivência de microrganismos, contribuindo para contaminação cruzada. Os utensílios e equipamentos contaminados são responsáveis por aproximadamente $16 \%$ dos surtos de intoxicações alimentares, por isso, é indispensável o controle higiênico e segurança sanitária durante o preparo dos alimentos para evitar a contaminação alimentar (Battaglini, et al., 2012).

$\mathrm{Na}$ manipulação de diversos alimentos pode ocorrer contaminação devido à forma irregular no manuseio dos utensílios, aumentando o risco da transmissão de microrganismos de um alimento para o outro, na maioria dos casos a contaminação ocorre pela inadequada higienização, dentre esses utensílios um dos principais são as tábuas de corte, as de vidro, plástico e madeira, são as mais utilizadas, porém a que possui maior risco de contaminação é a de madeira, por ser mais difícil a higienização e por absorver os resíduos pelas aberturas dos cortes, podendo armazenar muitos fungos e bactérias na superfície, portanto, é difícil a eliminação desses microrganismos apenas pelo enxágue (Pieniz, et al., 2019).

O ideal é utilizar diferentes tábuas para cada tipo de alimento, deixando-as reservadas para utilizarem todas às vezes naquele alimento específico, evitando a contaminação cruzada entre eles, uma vez que a manipulação de forma errada dos alimentos é um risco à saúde. Geralmente os restos de alimentos e com presença de água, possibilita o desenvolvimento de biofilmes bacterianos que podem conter microrganismos patogênicos, como fungos, protozoários e vírus (Battaglini, et al.,2012; Oliveira \& Siliano, 2017).

Algumas pesquisas, realizadas por, Abreu, \& Cabral, (2005), Battaglini, et. al., (2012) e Oliveira, \& Siliano, (2017), mostraram que tábuas de corte tem um grande acúmulo de bactérias e fungos, desta forma, qual seria o tipo mais indicado para a utilização na preparação dos produtos alimentícios de maneira mais segura?

Justifica-se a presente pesquisa pela dificuldade em encontrar bibliografias que discutem em especificidade este assunto, o que torna essa revisão integrativa uma importante colaboração, pois apresenta dados sobre os riscos de contaminações que possam ocorrer durante a utilização de tábuas de cozinha, pois os diversos cortes nesses utensílios tornamse um local hospitaleiro para microrganismos e desta forma, torna-se um meio potencial de contaminação em diversos alimentos, possibilitando o desenvolvimento de Doenças Transmitidas por Alimentos (DTA).

Esta pesquisa tem como objetivo identificar o nível de contaminação por microrganismos nos diversos tipos de tábuas de corte, e o tipo mais adequado para a utilização de forma segura. 


\section{Metodologia}

Este estudo foi desenvolvido por meio de uma revisão integrativa em artigos científicos encontrados nas bases de dados eletrônicas, Google Acadêmico, PubMed e SciELO (Scientific Electronic Library Online) que abordavam a análise microbiológica de tábuas de corte, priorizando os artigos publicados na íntegra nos últimos dez anos, alguns desses estudos com publicação inferior a 2011 que foram utilizados continham informações indispensáveis para a presente estudo. A pesquisa foi desenvolvida entre os meses de fevereiro a outubro do ano de 2021, período em que foram pesquisados 67 artigos científicos, dentre estes, foram selecionados 22, utilizando como critério para a seleção informações relevantes sobre a contaminação de tábuas de corte de uso doméstico. A busca foi realizada utilizando os seguintes descritores: "Tábuas de corte", "Alimentos contaminados", "microrganismos" e "contaminação alimentar" com o operador booleano "AND”. Excluiuse desse estudo: Trabalhos de Conclusão de Curso, monografias, textos incompletos e trabalhos duplicados. Figura 1 apresenta o fluxograma da revisão de literatura.

Figura 1. Fluxograma da revisão de literatura.

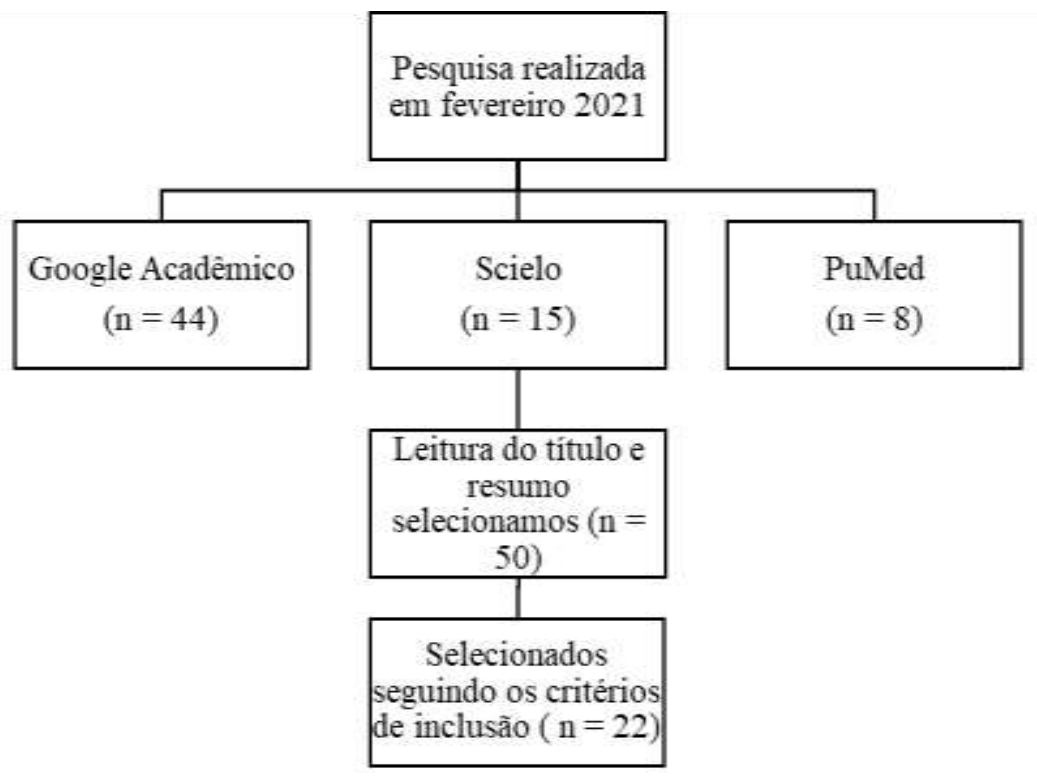

Fonte: Elaborado pelos autores.

\section{Resultados e Discussão}

Foi identificado que existem inúmeros trabalhos relatando a incidência de microrganismos patogênicos em quantidades elevadas fora do padrão da legislação brasileira em tábuas de corte de uso domiciliar, devido à falta de higiene na cadeia produtiva dos alimentos. O Quadro 1 apresenta os artigos pesquisados que realizaram pesquisas microbiológicas em tábuas de corte. 
Quadro 1. Contaminação por microrganismos em tábuas de corte de uso doméstico.

\begin{tabular}{|c|c|c|c|}
\hline Autores & Local do estudo & Objetivo & Resultado \\
\hline $\begin{array}{l}\text { Abreu, \& Cabral, } \\
2005 .\end{array}$ & Franca, SP & $\begin{array}{l}\text { Isolamento e identificação de } \\
\text { bactérias pertencentes ao grupo } \\
\text { Enterobacteriaceae em tábuas de } \\
\text { corte de madeira. }\end{array}$ & $\begin{array}{l}25 \text { amostras apresentaram crescimento bacteriano e } \\
\text { foram identificadas sete enterobactérias: Enterobacter } \\
\text { aglommerans, Salmonella sp., Serratia marcescens, } \\
\text { Citrobacter diversus, Escherichia coli, Enterobacter } \\
\text { cloacae enterobacter freundii. }\end{array}$ \\
\hline $\begin{array}{l}\text { Coelho, et al., } \\
2010 .\end{array}$ & Viçosa, MG & $\begin{array}{l}\text { Avaliar a contaminação por } \\
\text { microrganismos mesófilos aeróbios e } \\
\text { do grupo } B . \text { cereus no ar, em } \\
\text { superfícies de bancadas, utensílios, } \\
\text { equipamentos } \text { e mãos de } \\
\text { manipuladores } \text { em } \text { restaurantes } \\
\text { comerciais de maior demanda de } \\
\text { clientes no município de Viçosa } \\
\text { (MG). }\end{array}$ & $\begin{array}{l}\text { Os utensílios examinados foram facas de manipulação, } \\
\text { tábuas de altileno e cuba de aço inoxidável do balcão de } \\
\text { distribuição, escolhidos em função do alto risco de } \\
\text { causar toxinfecção. A contagem de mesófilos em } \\
\text { utensílios atingiu valor na ordem de } 10^{8} \text { UFC/ML, } \\
\text { valores muito acima ao recomendado pela American } \\
\text { Public Health Association (APHA), o que demonstra a } \\
\text { necessidade de medidas de controle higiênico-sanitários } \\
\text { urgentes. }\end{array}$ \\
\hline $\begin{array}{l}\text { Pinheiro, et. al., } \\
2010 .\end{array}$ & São Carlos, SP & $\begin{array}{l}\text { Avaliar a contaminação das tábuas de } \\
\text { corte utilizadas no preparo de } \\
\text { alimentos de uma instituição de } \\
\text { ensino superior em São Carlos-SP, } \\
\text { através de análises microbiológicas } \\
\text { realizadas a partir do método do } \\
\text { swab. }\end{array}$ & $\begin{array}{l}\text { Das tábuas analisadas, } 90 \% \text { estavam contaminadas, o que } \\
\text { indica uma condição higiênico-sanitária insatisfatória, } \\
\text { com a presença de mesófilos aeróbios, de bolores e } \\
\text { leveduras e da existência de enterobactérias. }\end{array}$ \\
\hline $\begin{array}{l}\text { Battaglini, et. al., } \\
2012 .\end{array}$ & Paranaguá, PR & $\begin{array}{l}\text { Avaliar a qualidade microbiológica da } \\
\text { água, dos alimentos in natura } \\
\text { congelados e expostos ao consumo e } \\
\text { as condições higiênico-sanitárias de } \\
\text { três restaurantes da Ilha do Mel } \\
\text { situada no município de } \\
\text { Paranaguá/PR. }\end{array}$ & $\begin{array}{l}\text { Das superfícies analisadas, } 72,2 \% \text { apresentaram } \\
\text { condições higiênico-sanitárias insatisfatórias. Tábuas } \\
\text { plásticas de corte, esponjas de louça, pias e os panos de } \\
\text { prato e de pia apresentaram as maiores médias de } \\
\text { contaminação. As verduras e os legumes foram os } \\
\text { principais responsáveis pela contaminação de tábuas e } \\
\text { pias. As tábuas plásticas de corte iniciaram os trabalhos } \\
\text { limpas, mas foram se contaminando durante o trabalho } \\
\text { devido à contaminação cruzada. Tábuas de corte e panos } \\
\text { de pia foram os pontos que apresentaram maiores médias } \\
\text { de contagens de leveduras: } 2,1 \text { x } 10^{4} \text { e } 1,5 \times 10^{4} \\
\text { UFC/cm }{ }^{2} \text {, respectivamente. }\end{array}$ \\
\hline $\begin{array}{l}\text { Ferrari, et. al., } \\
2013 .\end{array}$ & $\begin{array}{l}\text { Barra do Garças, } \\
\text { MT; Pontal do } \\
\text { Araguaia, MT e } \\
\text { Aragarças, GO. }\end{array}$ & $\begin{array}{l}\text { Realizar análise microbiológica de } \\
\text { diversas preparações servidas nas três } \\
\text { principais escolas do Médio Araguaia } \\
\text { (Barra do Garças, MT; Pontal do } \\
\text { Araguaia, MT e Aragarças, GO). }\end{array}$ & $\begin{array}{l}\text { Foram realizadas análises microbiológicas nos produtos } \\
\text { vendidos nas cantinas e em superfícies de equipamentos } \\
\text { e utensílios em contato com os alimentos, de acordo com } \\
\text { a disponibilidade da escola. Nos alimentos pesquisados, } \\
\text { bancada e isopor apresentaram presença de Coliformes } \\
\text { totais e Salmonella spp, porém as tábuas que foram } \\
\text { analisadas da escola municipal não houve crescimento de } \\
\text { microrganismos. }\end{array}$ \\
\hline $\begin{array}{l}\text { Oliveira, \& } \\
\text { Siliano, } 2017 .\end{array}$ & Santo André, SP & $\begin{array}{l}\text { Identificar o nível de contaminação } \\
\text { em tábuas de corte de acrílico e }\end{array}$ & $\begin{array}{l}\text { Foram analisadas } 20 \text { tábuas, das quais, } 10 \text { eram de } \\
\text { madeira e } 10 \text { de acrílico. As tábuas de acrílico }\end{array}$ \\
\hline
\end{tabular}




\begin{tabular}{|c|c|c|c|}
\hline & & madeira de uso domiciliar. & 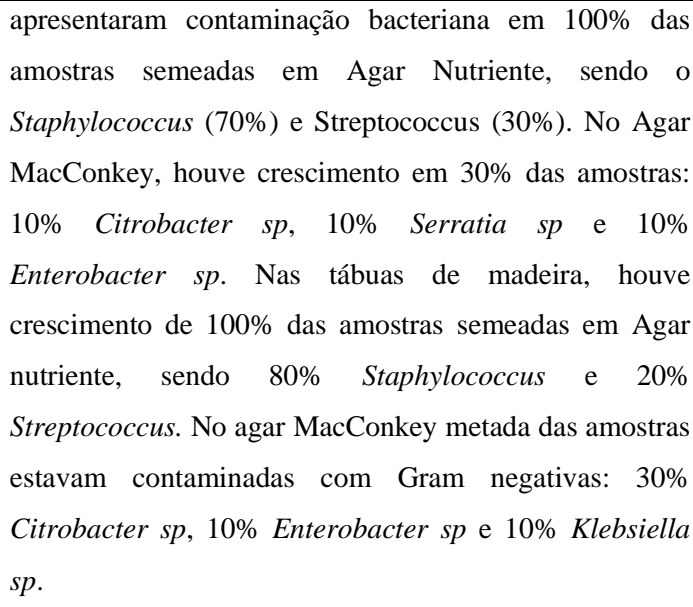 \\
\hline $\begin{array}{l}\text { Pieniz, et. al., } \\
2019 .\end{array}$ & Pelotas, RS & $\begin{array}{l}\text { Isolar e identificar bactérias de } \\
\text { equipamentos e superfícies de contato } \\
\text { com alimentos em uma Unidade de } \\
\text { Alimentação e Nutrição (UAN) } \\
\text { hospitalar, bem como avaliar a } \\
\text { condição sanitária. }\end{array}$ & $\begin{array}{l}\text { Foi identificado a adesão de microrganismos (formação } \\
\text { de biofilme) em tábuas de corte de polietileno (utilizadas } \\
\text { para corte de carne e de vegetais). Microrganismos } \\
\text { aeróbios mesófilos, leveduras, fungos, Sthapylococcus } \\
\text { coagulase-positivos, coliformes, coliformes fecais e } \\
\text { Escherichia coli estavam presentes em superfície de } \\
\text { mesas do refeitório, superfícies de bancada e tábuas de } \\
\text { corte usadas para manuseio de carne ou vegetais e, em } \\
\text { equipamentos como micro-ondas e refrigeradores. }\end{array}$ \\
\hline $\begin{array}{l}\text { Braccini, et. al., } \\
2020 .\end{array}$ & Santa Maria, RS & $\begin{array}{l}\text { Analisar os riscos à saúde através da } \\
\text { contagem de microrganismos } \\
\text { contaminantes em tábuas de corte de } \\
\text { restaurantes do Município de Santa } \\
\text { Maria, RS. }\end{array}$ & $\begin{array}{l}\text { Foram analisadas } 15 \text { amostras de tábuas de corte usadas } \\
\text { no preparo de alimentos crus em restaurantes. Os } \\
\text { resultados microbiológicos indicaram que } 35,30 \% \\
\text { apresentaram contagem total de mesófilos aeróbios igual } \\
\text { ou inferior a } 1000 \mathrm{UFC} / \mathrm{cm}^{2} \text {, e que } 64,70 \% \text { foram } \\
\text { insatisfatórias devido à presença de microrganismos com } \\
\text { contagens superiores a } 1000 \mathrm{UFC} / \mathrm{cm}^{2} \text {. }\end{array}$ \\
\hline Lara, et. al., 2019. & Cuiabá, MT & $\begin{array}{l}\text { Isolar enterobactérias, principalmente } \\
\text { as termotolerantes, presentes nas } \\
\text { superfícies de facas, bandejas e tábuas } \\
\text { utilizadas no manuseio de carne em } \\
\text { açougues. }\end{array}$ & $\begin{array}{l}\text { Entre os utensílios utilizados no manejo de carne de } \\
\text { aves, a faca obteve um maior crescimento de } \\
\text { enterobactérias }\left(4,36 \times 10^{4} \mathrm{UFC} \mathrm{cm}^{2}\right) \text {. A tábua de cortar } \\
\text { carne de porco apresentou } 7,44 \times 10^{4} \mathrm{UFC} / \mathrm{cm}^{2} \text {. O alto } \\
\text { crescimento de enterobactérias é justificado pelos sulcos } \\
\text { contidos nessas ferramentas, falta de manutenção e } \\
\text { higiene. }\end{array}$ \\
\hline $\begin{array}{l}\text { Caro-Hernández \& } \\
\text { Tobar, } 2020 .\end{array}$ & Cali, Colômbia & $\begin{array}{l}\text { Avaliar a segurança microbiana de } \\
\text { superfícies em contato com alimentos } \\
\text { em restaurantes formais e informais e } \\
\text { barracas de comida de rua localizadas } \\
\text { próximas a um campus universitário. }\end{array}$ & $\begin{array}{l}\text { Os resultados mostraram contaminação cruzada, com } \\
\text { altas percentagens de bactérias aeróbias mesófilas, a } \\
\text { identificação bacteriana demonstrou a presença de vários } \\
\text { gêneros da família Enterobacteriaceae. }\end{array}$ \\
\hline $\begin{array}{l}\text { Rodrigues, et al., } \\
2017 .\end{array}$ & Londrina, PR & $\begin{array}{l}\text { Avaliar as condições microbiológicas } \\
\text { dos alimentos, superfícies e utensílios } \\
\text { utilizados no preparo das refeições no } \\
\text { Restaurante Universitário (RU) da } \\
\text { Universidade Tecnológica Federal do }\end{array}$ & $\begin{array}{l}\text { Além de alimentos e outros utensílios, foi analisado, } \\
\text { tábua de franjo suja a qual apresentou presença de } \\
\text { Staphylococcus e tábua suja que apresentou presença de } \\
\text { E. coli. As saladas cruas foram os alimentos mais } \\
\text { contaminados, seguido das saladas cozidas. Os alimentos } \\
\text { submetidos à alta temperatura e servidos quentes }\end{array}$ \\
\hline
\end{tabular}


Research, Society and Development, v. 10, n. 13, e388101321322, 2021

(CC BY 4.0) | ISSN 2525-3409 | DOI: http://dx.doi.org/10.33448/rsd-v10i13.21322

\begin{tabular}{|c|c|c|c|}
\hline & & Paraná, campus Londrina - PR & $\begin{array}{l}\text { apresentaram-se adequados para o consumo, sem } \\
\text { oferecer riscos à saúde da comunidade acadêmica }\end{array}$ \\
\hline $\begin{array}{l}\text { Mezzari \& } \\
\text { Ribeiro, } 2012 .\end{array}$ & Campo Mourão, PR & $\begin{array}{l}\text { Detectar possíveis falhas no } \\
\text { processamento de alimentos de uma } \\
\text { escola pública do município de } \\
\text { Campo Mourão - Paraná, verificando } \\
\text { as não-conformidades com relação } \\
\text { às Boas Práticas de Fabricação que } \\
\text { podem levar à contaminação dos } \\
\text { alimentos, }\end{array}$ & $\begin{array}{l}\text { Nas tábuas de corte de carne houve presença de } \\
\text { Salmonella enquanto que, nas tábuas de corte de legumes } \\
\text { não apresentou a respectiva bactéria. A presença de } \\
\text { Salmonella em tábuas de corte indica que as } \\
\text { condições higiênico-sanitárias estão fora dos padrões } \\
\text { mínimos exigidos e é necessário um esclarecimento } \\
\text { sobre os perigos de contaminação de alimentos por meio } \\
\text { destes utensílios. }\end{array}$ \\
\hline Souza, et al., 2017. & Curitiba, PR & $\begin{array}{l}\text { Avaliar as condições microbiológicas, } \\
\text { de conservação e de higienização de } \\
22 \text { superfícies de corte de carnes em } \\
11 \text { supermercados em um município } \\
\text { da Região Metropolitana de Curitiba- } \\
\text { PR. }\end{array}$ & $\begin{array}{l}\text { Das } 22 \text { superfícies analisadas, } 59 \% \text { apresentavam muitas } \\
\text { ranhuras. Em relação aos produtos utilizados para a } \\
\text { higienização das superfícies de corte de carne, foi } \\
\text { observado a utilização de água e detergente de louças em } \\
45 \% \text { dos casos, água corrente em } 27 \% \text {, água sanitária em } \\
9 \% \text { e produtos específicos para este fim em } 18 \% \text {. Quanto } \\
\text { à análise microbiológica, evidenciou-se bactérias } \\
\text { heterotróficas mesófilas, bolores, leveduras e coliformes. }\end{array}$ \\
\hline
\end{tabular}

Fonte: Elaborado pelos autores.

As pesquisas apontam a prevalência de microrganismos aeróbios mesófilos, leveduras, fungos e bactérias da família Enterobacteriaceae, como pode ser observado na pesquisa de Lara, et. al., (2019), Caro-Hernandez \& Tobar, (2020) e Coelho, et al., (2010). Também foi identificado a contaminação de alimentos por coliformes totais e Salmonella spp. (Ferrari, et. al., 2013, Pieniz, et. al., 2019). Além desses microrganismos, foi observado a presença de Staphylococcus sp, em tábuas de corte, de acordo com a pesquisa de Oliveira \& Siliano, (2017) e Pieniz, et. al., (2019).

Segundo os estudos de Pinheiro, et. al., (2010) e Battaglini, et. al., (2012), os principais fatores de contaminação são, as inadequadas condições higiênico-sanitárias e o uso de diversos alimentos em uma mesma tábua, possibilitando a contaminação cruzada. Uma pesquisa realizada por Braccini, et. al., (2020) ressalta os resultados dos microrganismos encontrados em 15 tábuas de corte usadas no preparo de alimentos crus, onde 64,70\% apresentaram presença de microrganismos com contagens superiores a $1000 \mathrm{UFC} / \mathrm{cm}^{2}$ de mesófilos aeróbios. Outra pesquisa semelhante, realizada por de Oliveira \& Siliano, (2017) foi analisado 20 tábuas de corte, sendo 10 de madeira e 10 de acrílico, onde, 100\% desses utensílios apresentaram bactérias do grupo Gram positivo já as tábuas de madeira apresentaram 50\% de bactérias do grupo Gram negativo, enquanto que, as de acrílico apresentaram apenas $30 \%$ desse grupo de bactéria.

\section{Doenças Transmitidas por Alimentos (DTA)}

A Organização Mundial de Saúde afirma que ocorram todos os anos 1,5 bilhões de casos de toxi-infecções alimentares, sendo considerada uma alto incidência destas doenças na população. As Doenças Transmitidas por Alimentos (DTA), geralmente têm origem nos procedimentos de higienização inadequados, relacionados aos manipuladores e à utilização de matérias-primas de má qualidade (Mezzari, \& Ribeiro, 2012).

As DTA são doenças causadas pela ingestão de alimentos contaminados, com perigos biológicos, físicos ou químicos em condições de causar doenças, a qualidade também se refere a alimentos ricos em nutrientes, por isso durante as preparações devem ser tomados os cuidados necessários para evitar a contaminação por microrganismos patogênicos e evitar possíveis 
surtos de DTA relacionados a episódios em que uma ou mais pessoas apresentam sintomas clínicos semelhantes, após ingerirem alimentos de mesma origem e procedência (Rodrigues, et al., 2017).

A contaminação dos alimentos com patógenos/toxinas e sua persistência e multiplicação tornou-se uma relevante preocupação de saúde pública. Os agentes patogênicos de origem alimentar são um desafio para a saúde pública, especialmente para os grupos de risco que incluem recém-nascidos, gestantes, idosos e pessoas imunocomprometidas. As infecções de origem alimentar mais usualmente conhecidas são aquelas causadas por bactérias, incluindo Salmonella spp., Campylobacter spp., Escherichia coli O157:H7, Listeria monocytogenes, Staphylococcus aureus; vírus da hepatite A, rotavírus, dentre outras (Fröder, et al., 2021)

A origem dessas DTA geralmente é ocasionada no momento da manipulação dos alimentos, as ocorrências clínicas decorrentes da ingestão de alimentos que podem estar contaminados com microrganismos patogênicos, substâncias químicas ou que tenham em sua constituição substâncias tóxicas, são condições potenciais de agravo à saúde do consumidor. A segurança alimentar envolve a quantidade, a produção, o acesso geral aos alimentos, as doenças, aspectos nutricionais referentes à composição, à qualidade e ao aproveitamento biológico e à qualidade dos alimentos quanto às condições sensoriais, físico-químicas e microbiológicas (Arevabini \& Taverna, 2018).

As tábuas de corte, indispensáveis na cozinha e fundamentais durante o preparo dos alimentos, são propícias para a acumulação de microrganismos prejudiciais ao organismo humano. Elas têm sido um utensílio que apresenta maior índice de microrganismos, bactérias e fungos presentes nas superfícies dos seus cortes que são ocasionados na hora do preparo dos alimentos, mesmo após a lavagem básica não são retiradas todas as impurezas, o que favorece toxi-infecções alimentares ou DTA (Rodrigues, et al., 2017).

Durante a intoxicação o organismo reage para combater as toxinas e em resposta a esse processo surge alguns sintomas, os mais comuns, são, vômitos, dor ou cólicas na região abdominal, diarreia, desidratação, entre outros, essas reações podem ocorrer após a ingestão de alimentos contaminados, ou alguns dias, até mesmo semanas depois, se não tratada adequadamente. (Abreu \& Cabral, 2005)

Milhares de pessoas, diariamente ficam doentes por consumirem alimentos com algum tipo de contaminação, pois os microrganismos são os principais agentes deteriorantes dos alimentos causando prejuízo à saúde do consumidor. Os adultos reagem melhor a esse tipo de contaminação que pode durar apenas alguns dias, mas as sequelas em crianças e idosos são consequências mais graves levando até a morte, portanto, deve-se ter boas práticas de higiene para evitar as doenças transmitidas por alimentos (Jung, et al., 2010).

\section{Contaminação Cruzada}

A forma como os alimentos são manipulados, o contato em superfícies, utensílios e equipamentos insuficientemente limpos poderão ocasionar a denominada contaminação cruzada, ou seja, é o processo em que ocorre à transferência de microrganismo de um alimento contaminado para um outro alimento que não esteja contaminado. A adesão de bactérias em ranhaduras de tábuas de corte e em superfícies de manipulação de alimentos possibilitam a contaminação entre os alimentos ali manipulados. (Arevabini \& Taverna, 2018; Ribeiro, et al., 2008).

O consumo de alimentos crus ou mal lavados possui um maior risco de transmissão de patógenos, favorecendo uma intoxicação ou contaminação alimentar causada por fungos, bactérias, toxinas e outros microrganismos que vão afetar o organismo humano. Sabe-se que os microrganismos patogênicos podem estar presentes em partículas de alimentos ou em água sobre os utensílios lavados inadequadamente, no entanto, uma boa higiene pessoal e boas práticas no manuseamento sanitário no local de preparo dos alimentos são essenciais em qualquer programa de prevenção para a segurança alimentar (Pieniz, et al., 2019; Souza, et. al., 2017). 
O uso contínuo de uma mesma tábua de corte para coisas diferentes respectivamente é um dos problemas que causa propagação dos microrganismos, pois ao cortar uma carne crua e em seguida cortar verduras, torna-se um meio para contaminação cruzada devido a transmissão de bactérias. As carnes passam no vapor por altas temperaturas durante o preparo, podendo combater as bactérias, porém algumas verduras que são ingeridas naturalmente são mais fáceis de contaminar, por isso devem ter o devido cuidado para evitar a ingestão de microrganismos junto aos alimentos (Machado, et al., 2016).

O manipulador de alimento pode ser uma via de contaminação dos alimentos, é considerado responsável por até $26 \%$ dos surtos de enfermidades bacterianas transmitido por alimentos a partir do processamento incorreto, tendo em vista que as mãos dos manipuladores representam alto risco pela deficiência da higienização, causando insegurança na qualidade dos alimentos e propagando contaminação microbiológica entre os utensílios (Coelho, et al., 2007).

A habilidade das bactérias em se aderir à superfície de contato dos utensílios compromete a higiene, limpeza e desinfecção das tábuas de corte, quando não realizadas corretamente, contribuindo para que microrganismos patogênicos sejam veiculados nos alimentos visto que, para o benefício da saúde humana é necessário utilizar a prática de biossegurança nas cozinhas de forma geral, a fim de evitar contaminação, proteger contra os riscos adversos de exposição na manipulação, prevenir contaminação cruzada e transmissão de doenças contagiosas (Pinheiro, et al., 2010).

\section{Higienização e uso correto de tábuas de corte}

Tratando-se de cozinhas domésticas ou industriais, as tábuas de corte é um indicador frequente de infecções e contaminações cruzadas, pois são utilizadas sucessivamente por diversas vezes para preparação de vários alimentos sem nenhuma limpeza ou descontaminação, se tornando um fator comum de intoxicações alimentares pela proliferação de microrganismos, pois a contaminação ocorre durante o manuseio dos utensílios ou até mesmo a falta de higiene de quem está preparando os alimentos, portanto a prevenção ocorre conforme as medidas adequadas de limpeza, a utilização dos Equipamentos de Proteção Individual (EPI) necessários e a aplicação das boas práticas de manipulação (Battaglini, et al., 2012; Sanches, 2007).

A higienização trata-se de uma operação que compreende duas etapas, a limpeza e a desinfecção, conjunto de medidas necessárias para garantir a segurança e a perfeita qualidade dos alimentos em todos os estágios de cultivo, produção, transporte e distribuição. Visa à redução de microrganismos presentes na pele a níveis seguros, por meio da lavagem das mãos com sabonete antisséptico ou por uso de agente antisséptico após a lavagem e secagem das mãos (Arevabini \& Taverna, 2018).

O tipo de tábua de corte mais utilizada e que há maior facilidade de proliferação de microrganismos é a de madeira, justamente pela facilidade de cortes que causam leves aberturas propícias para o acúmulo de restos de comidas como carnes, pequenos restos de verduras e legumes que não saem apenas com enxague, para isso uma das formas de prevenção é obter uma tábua para cada objetivo e não negligenciar a limpeza antes e após o uso dos utensílios. E outras medidas de controle são as lavagens das mãos com água e sabão ou o uso de produtos saneantes, como o álcool líquido ou em gel 70\% e a prática de desinfecção das superfícies onde ficam apoiadas as tábuas como mesas, balcões e pias. Para uma correta higienização de tábuas de corte ou outro utensílio, pode-se enxaguá-las em uma solução contendo uma colher de sopa de água sanitária sem perfume a 2\% por litro de água (Caro-Hernández \& Tobar, 2019; Blanc \& Azeredo, 2014).

$\mathrm{O}$ ato de lavagem das tábuas é muito importante entre um alimento e outro. De acordo com a Agência Nacional de Vigilância Sanitária (ANVISA) o mais correto seria designar cada utensílio a sua determinada função, por exemplo, placas de corte de polietileno exclusivamente para obter tábuas de cores diferentes, onde cada cor é utilizada para o preparo de um único tipo de alimento, mesmo que ocorra possíveis contaminações, a generalização e a gravidade dos microrganismos são menores, podendo ter resultados positivos (Ferreira, et al., 2008). 
Em uma pesquisa realizada por meio de entrevistas com mulheres de classe média à alta (População A) e mulheres de classe média à baixa (População B) foi evidenciado que em relação ao uso de diferentes tábuas de corte (uma somente para carnes, outra para hortaliças), 67 e 77\% da população A e B respectivamente não utilizam tábuas de corte diferentes para cada tipo de alimento. Em ambas as populações, apenas 1\% afirmaram não utilizar tábuas de corte, pois tem o hábito de cortar os alimentos no prato. É importante que todos saibam que se deve utilizar apenas uma tábua para alimentos crus que serão cozidos, como carnes, e outra apenas para alimentos prontos para comer, como pão, frutas frescas e peixes cozidos, prevenindo-se assim contaminações cruzadas pela tábua de corte ou por qualquer alimento contaminado (Ludwig, \& Tanji, 2017).

\section{Considerações Finais}

A análise das tábuas de corte para avaliação quanto à sua utilização de forma segura é imprescindível, uma vez que microrganismos patogênicos que possivelmente estão presente nesses utensílios podem gerar prejuízos à saúde humana através do consumo de alimentos contaminados.

Os resultados das pesquisas demonstraram a presença de contaminações e/ou crescimento microbiano presente em tábuas de corte, evidenciou-se a prevalência de microrganismos aeróbios mesófilos, leveduras, fungos e bactérias da família Enterobacteriaceae. Foi enfatizado que as bactérias se adaptam as superfícies inertes causando alterações prejudiciais em alimentos quando em contato. Todos estes fatores são discutidos pelos autores que na maioria das vezes chegaram a conclusões semelhantes e seus trabalhos acabam por se tornarem complemento ou consolidação dos fatores identificados em trabalhos iniciais.

Através das informações apresentadas no presente artigo e com a correta orientação a população, torna-se um processo relevante para minimizar os ricos de contaminações alimentares, eventuais desvantagens econômicas para os produtores e a garantia na qualidade dos alimentos. A adoção de práticas sanitárias remete a um processo minucioso e que requer constante monitoramento por parte de quem vende e de quem fiscaliza.

Para prevenção de contaminações cruzadas e doenças transmitidas por alimentos é de suma importância a adoção de tábuas de polietileno coloridas, onde cada cor será reservada para cada tipo de alimento além de sempre higienizar as tábuas antes e após o seu uso bem como os locais em que as mesmas ficam guardadas.

\section{Referências}

Abreu, S. C., \& Cabral, M. M. W. (2005). Análises microbiológicas de placas de corte de madeira para identificação de bactérias pertencentes ao grupo das enterobacteriaceae. Investigação - Revista Científica da Universidade de Franca, 5(1-6), 132-138. https://doi.org/10.26843/investigacao.v5i1-6.205

Arevaini, C. A., \& Taverna, L. G. (2018). Higiene e Controle de Qualidade de Alimentos. Batatais, SP: Ação Educacional Claretiana.

Battaglini, A. P. P., Fagnani, R., Tamanini, R., \& Beloti, V. (2012). Qualidade microbiológica do ambiente, alimentos e água, em restaurantes da Ilha do Mel/PR. Semina: Ciências Agrárias, 33(2), 741-754. DOI: 10.5433/1679-0359.2012v33n2p741

Blanc, P. A., \& Azeredo, D. R. P. (2014). A Segurança de Alimentos no Contexto do Idoso. Revista Brasileira de Tecnologia Agroindustrial, 8(2), 1336-1347. DOI: $10.3895 /$ S1981-36862014000200004.

Braccini, V. P, Ely, V. L., Silva, S. F., \& Vargas, A. C. (2020). Avaliações de tábuas de corte utilizadas em restaurantes de Santa Maria-RS. Anais do Salão Internacional de Ensino, Pesquisa e Extensão, 10(2). Recuperado de: https://periodicos.unipampa.edu.br/index.php/SIEPE/article/view/100802.

Caro-Hernández, P. A., \& Tobar, J. A. (2020). Análisis microbiológico de superficies en contacto con alimentos. Entramado, 16(1), 240-249. https://dx.doi.org/10.18041/1900-3803/entramado.1.6126

Coelho, A. Í. M., Milagres, R. C. R. M., Martins, J. F. L., Azeredo, R. M. C., \& Santana, Â. M. C. (2010). Contaminação microbiológica de ambientes e de superfícies em restaurantes comerciais. Ciência \& Saúde Coletiva, 15(Supl. 1), 1597-1606. https://doi.org/10.1590/S1413-81232010000700071 
Ferrari, C. K. B., Assumpção, C. F., Morzelle, M. C., Ferrari, G. S. L., \& Souza, É. C. (2013). Avaliação microbiológica em alimentos de cantinas escolares na região do médio Araguaia (MT/GO). Revista Baiana de Saúde Pública, 37(1), 45-56. DOI: https://doi.org/10.22278/2318-2660.2013.v37.n1.a166

Ferreira, L. M. F., Trancoso, S. C., Riciardi, P. M., Cavalli, S. B., \& Proença, R. P. C. (2008). Utensílios de cortes de cores diferenciadas: uma proposta para prevenir contaminação cruzada na produção de refeições. Nutrição em Paula, 93, 1- 6. Recuperado de: https://nuppre.paginas.ufsc.br/files/2014/04/2008Ferreira-et-al.pdf

Fröder, H., Martins, M. L. M., Oliveira, W. C., \& Mattia, J. L. Contaminação por patógenos na alimentação de rua: Revisão sistemática. Research, Society and Development, 10(9), 1 - 8. DOI: http://dx.doi.org/10.33448/rsd-v10i9.18177

Jung, A., Labes Girardi, C. F., \& Susin, M. G. (2010). Higiene e Segurança do Alimento: Cartilha Orientativa. Sapiranga, RS: Secretaria Municipal de Educação de Sapiranga. Recuperado de: http://plataforma.redesan.ufrgs.br/biblioteca/pdf_bib.php?COD_ARQUIVO=14796.

Lara, E., Felix, C. L, Duarte, T. D, \& Vivi, V. K (2019). Microbiological analysis of surfaces in butchers of the municipal market of Cuiabá. Journal Health NPEPS, 4 (2), 253-267. Recuperado de: https://periodicos.unemat.br/index.php/jhnpeps/article/view/4047

Ludwig, K. M., \& Tanji, R. (2017). Avaliação dos hábitos de higiene, conservação e manipulação de alimentos na população de Assis-SP. Revista Hórus, 10(1), 80-93. Recuperado de: https://portal.estacio.br/docs/revista-horus/2015/HORUS_2015_OK_KARIN.pdf

Machado, G. B., Moura, S. V., Fortes, T. P., Felix, S. R., Timm, C. D., \& Silva, É. F. (2016). Impacto da salmonelose na suinocultura e suas implicações em saúde pública. Arquivos do Instituto Biológico, 83. Recuperado de https://doi.org/10.1590/1808-1657000472014.

Mezzari, M. F., \& Ribeiro, A. B. (2012). Avaliação das condições higiênico-sanitárias da cozinha de uma escola municipal de Campo Mourão-Paraná. SaBios - Revista de Saúde e Biologia, 7(3). Recuperado de: https://revista2.grupointegrado.br/revista/index.php/sabios/article/view/647.

Oliveira, L. R., \& Siliano, P. R. (2017). Análise microbiológica em tábuas de corte de madeira e de acrílico de cozinhas domiciliares. Revista UNILUS Ensino e Pesquisa, 14(34), 165-168. Recuperado de: http://revista.unilus.edu.br/index.php/ruep/article/view/800/u2017v14n34e800

Pieniz, S., Rodrigues, D. F., Arndt, R. M., Mello, J. F., Rodrigues, K. L., Andreazza, R., Camargo, F. A. O. \& Brandelli, A. (2019). Molecular identification and microbiological evaluation of isolates from equipments and food contact surfaces in a hospital Food and Nutrition Unit. Brazilian Journal of Biology, 79(2), 191-200. https://doi.org/10.1590/1519-6984.175350.

Pinheiro, M. B., Wada, T. C., \& Pereira, C. A. M. (2010). Análise microbiológica de tábuas de manipulação de alimentos de uma instituição de ensino superior em São Carlos, SP. Revista Simbio-Logias, 3(5), 115-124. Recuperado de: https://www1.ibb.unesp.br/Home/Departamentos/Educacao/SimbioLogias/analise_microbiologica_tabuas_manipulacao_alimentos_instituicao_ensino_superior.pdf

Ribeiro, D. R., Rossi, E. M., Sardiglia, C. U., \& Cunha, F. B. D. (2008). Detecção de Enterobacteriaceae e Staphylococcus aureus em restaurantes comerciais. Higiene alimentar, 22(160), 77-80.

Rodrigues, J. M., Mucinhato R. M. D, Furlaneto-Maia, L., Gomes, J. P., \& Oliveira, A. F. (2017). Avaliação das condições microbiológicas de alimentos, superfícies e utensílios utilizados no preparo de refeições em um restaurante universitário. Tópicos em ciências e tecnologia de alimentos: resultados de pesquisas acadêmicas (pp. 157 - 186). São Paulo, SP: Blucher.

Sanches, A. C. (2007). Avaliação do desenvolvimento microbiano em superfície de manipulação de alimentos. Higiene. alimentar, 21(154), 30-33.

Souza, V. R., Prieto, A. H., Santos, D. M., Abrahão, W. M., Borges, E. M. J., \& Lopes, M. O. (2017). Avaliação das condições higiênicas de superfícies de corte de carne em supermercados de um município da região metropolitana de Curitiba-PR. Archives of Veterinary Science,22(1), 01-09. DOI: http://dx.doi.org/10.5380/avs.v22i1.48227 